\title{
SENSIBILIDADE DO ESTUDO DE VIABILIDADE TÉCNICO-ECONÔMICA DE UMA AGROINDÚSTRIA DE PROCESSAMENTO DE COCO
}

\author{
Carlos Enrique de Medeiros Jeronimo ${ }^{1}$ \\ Mateus Soares Coelho ${ }^{2}$
}

\begin{abstract}
RESUMO: Neste trabalho foi desenvolvido o estudo de viabilidade técnica-econômica da implantação de uma unidade produtiva do ramo de beneficiamento de coco, para produção de leite de coco e coco ralado desidratado. O estudo foi centrado na avaliação dos investimentos necessários e na avaliação da capacidade produtiva da unidade, sendo realizadas simulações de produção a partir de dados técnicos, subsidiados pela obtenção de um balanço de massa específico e com alta precisão. São apresentados os resultados obtidos para os parâmetros econômicos, tendo a estruturação atestada em avaliação de mercado realizada, sendo definida uma política de produção, bem como, os mercados e produtos de maiores atratividades (sensibilidade). As simulações realizadas foram obtidas para o processamento de 7 e 14 toneladas de coco por 8 horas de processamento. $\mathrm{O}$ desenvolvimento do estudo partiu da avaliação dos investimentos necessários e na avaliação da capacidade produtiva da unidade, sendo realizadas simulações de produção para o processamento de 30 a 50 mil cocos por mês (11.726 kg de polpa/ mês), tendo-se o investimento em uma estrutura de 14 toneladas por 8 horas de operação, os melhores desempenhos para o payback, TIR e VPL.
\end{abstract}

Palavras-Chave: coco, análise econômica, sensibilidade.

ABSTRACT: This work presents the study of technical and economic feasibility of implementing a production unit in the business of processing coconut to produce coconut milk and desiccated coconut. The study concentrated on evaluating the investment required and the assessment of the productive capacity of the unit, simulated production from technical data, subsidized by obtaining a mass balance specific and with high precision. Presents the results obtained for the economic parameters, and the structuring attested in market assessment performed, with a defined policy on production, as well as markets and products of higher attractiveness (sensitivity). The simulations were obtained for the processing of 7:14 tonnes coconut processing for 8 hours. The development of the study was based on assessment of necessary investments and assessing the productive capacity of the unit, simulated production for processing 30 to 50 thousand coconuts per month $(11,726 \mathrm{~kg}$ pulp/month) and it was the investment in a structure of 14 tons per 8 hours of operation, the best performance for the payback, IRR and NPV.

Keywords: coconut, economic analysis, sensitivity.

\footnotetext{
${ }^{1}$ Doutorado em Engenharia Química pela Universidade Federal de Rio Grande do Norte (UFRN). Engenheiro de Processamento de Petróleo da Petrobras. E-mail: c_enrique@ hotmail.com

${ }^{2}$ Bacharel em Direito. E-mail: mateusscoelho@ hotmail.com
}

Recebido em: 25/03/2012

Aceito em: 04/05/2012 


\section{INTRODUÇÃO}

O Brasil, atualmente, possui uma tendência de crescimento do cultivo do coqueiroanão, distribuídos, praticamente, em todo o território nacional. Apesar do cultivo do coqueiro estar sendo estimulado e introduzido em várias regiões do país, as maiores plantações e produções se concentram na faixa litorânea do Nordeste e parte da região Norte do Brasil (EMBRAPA, 2011).

Favorecida pelas condições de tropicalidade climática, ambas as regiões (norte e nordeste) detêm próximos dos $70 \%$ da produção do coco brasileiro. O Brasil possui cerca de 280 mil hectares cultivados com coqueiro, distribuídos, praticamente, em quase todo o território nacional com produção equivalente a dois bilhões de frutos (FAO, 2011). Mesmo havendo incremento na área colhida desde 1990, o que se verifica é o aumento vertiginoso (superior a 800\%) de produção a partir do final da década de 1990.

O cultivo do coco é uma das práticas arraigadas no histórico dos agronegócios do Brasil, em especial da região nordeste. E como em todo ciclo produtivo a busca de produtos com maior valor agregado e tempos de vida útil mais longo, se tornam uma constante. A industrialização de beneficiamento de coco é uma atividade atrativa com forte potencial econômico, tendo nos dias atuais, uma definição exata de como esse tipo de indústria deve operar, dentro de um contingente bastante vasto de produtos acabados.

O coqueiro é uma árvore da qual tudo se aproveita. A camada externa serve para fabricar substrato agrícola, capachos, brochas, escovas, estofamentos e tecidos grossos para sacos. A casca dura e usada no artesanato e como fonte de energia térmica (combustível para caldeiras). As partes comestíveis do fruto são: a polpa branca e a água, que podem ser consumidas quando o fruto ainda está verde ou depois de maduro.

De acordo com Cuenca et al. (2002) estima-se que a produção brasileira é comercializada da seguinte forma: $35 \%$ destinam-se às agroindústrias, que produzem principalmente coco ralado e leite de coco; $35 \%$ destinam-se aos mercados Sudeste/Sul; e, $30 \%$ restante ficam no mercado nordestino.

Os produtos do coco no Brasil, tal como na maior parte do mundo, são matériaprima de relevância na indústria de muitos produtos alimentares, desde fábricas de bolachas, doces, iogurtes, sorvetes, restaurantes industriais e até pequenas confeitarias e lanchonetes. Destaquem-se os produtos de maior demanda no mercado brasileiro como: coco inteiro, água e polpa de coco verde, leite de coco, coco ralado e amêndoa de coco 
maduro (MORORÓ, 2012). O farelo é destinado ao consumo animal. O óleo é usado na alimentação e na fabricação de sabão, cosméticos, detergentes.

Os novos investimentos têm tendenciosamente grandes chances de retorno significativo, contudo, é necessário observar uma série de requisitos básicos, começando por um bom planejamento do negócio, isso envolvendo questões: técnicas, ambientais, sanitárias, econômicas e financeiras. Bem como, o subsidio de estudos robustos que minimizem os riscos econômicos associados a tais investimentos, tais como desenvolvido por Magalhães et al (2004).

Diante disso, surgem as ferramentas de análise de viabilidade técnica e econômica de projetos, cujo desempenho é associado ao grau de maturidade das informações e bases do levantamento da composição de elementos que auxiliam nas oscilações de custos, receitas e dinâmica do mercado.

Os parâmetros de respostas aos estudos de viabilidade econômica já apresentam uma consolidação no meio científico, tendo-se os métodos de fluxos de caixa descontados preferidos pelos analistas, em especial o método VPL - Valor Presente Líquido (também chamado de NPV - Net Present Value) e o método TIR - Taxa Interna de Retorno (também conhecido por IRR - Internal Rate of Return). Hirschfeld (1984) e Balarine (1996), entre outros, confirmam esta preferência, dando consistência à aplicação de taxas de desconto aos fluxos de caixa em análise.

Cadman \& Austin-Crowe (1994) destacam que as técnicas tradicionais de avaliação prévia de empreendimentos utilizam formato simples, comparativo entre custos e receitas totais, buscando verificar se os projetos produzirão taxas de retorno adequadas. Como o tempo é elemento significativo e a incidência de custos e receitas ocorrem em diferentes momentos, é importante descontar (ou capitalizar) tais ocorrências para uma data única, usualmente a data do estudo de viabilidade. Para tanto, identifica-se a taxa de atratividade e/ou custos financeiros incidentes, para aplicação dos métodos disponíveis através da Engenharia Econômica.

Entretanto, as variáveis de interesse econômico num EVTE (VPL, TIR e tempo de retorno) sofrem fortes influências das variáveis operacionais, e quase sempre a literatura não disponibiliza meios para um fiel levantamento e construção dos cenários de riscos associados, daí a necessidade de estudos da sensibilidade das variáveis que acompanham e suportam o estudo.

Apoiado nessa premissa o presente trabalho foi elaborado avaliando a viabilidade técnica-econômica-financeira da implantação de uma unidade produtiva do ramo de 
beneficiamento de coco (com capacidade nominal dos principais equipamentos envolvidos), para produção de leite de coco e coco ralado desidratado. O estudo foi centrado na avaliação dos investimentos necessários e na avaliação da capacidade produtiva da unidade, sendo realizadas simulações de produção a partir de dados técnicos, subsidiados pela obtenção de um balanço de massa específico e com alta precisão. São apresentados os resultados obtidos para os parâmetros econômicos, tendo a estruturação atestada em avaliação de mercado realizada, sendo definida uma política de produção, bem como, os mercados e produtos de maiores atratividades (sensibilidade).

As simulações realizadas foram obtidas para o processamento de 7 e 14 toneladas (modelos disponíveis para os 6 principais fornecedores) de coco por 8 horas de processamento.

O desenvolvimento do estudo partiu da avaliação dos investimentos necessários e na avaliação da capacidade produtiva da unidade, sendo realizadas simulações de produção para o processamento de 30 a 50 mil cocos por mês (11.726 kg de polpa/ mês). O modelo sugerido foi todo estruturado para uma cadeia tecnologicamente limpa, com o aproveitamento de todo o rejeito na forma de combustível para a alimentação das caldeiras que irá abastecer a empresa de vapor e potencializando-se para a geração de energia elétrica.

\section{PREMISSAS ADOTADAS}

\subsection{Critérios de Localização}

Sendo uma empresa do ramo de atividade de produtos alimentícios, alguns critérios sanitários são preponderantes na escolha da área, isso a fim de evitar problemas com pragas e contaminações externas. Além dessas questões, os aspectos ambientais devem ser considerados, para minimizar problemas relacionados a impactos ambientais e a custos de tratamento de efluentes.

Nesses requisitos foram observados os seguintes aspectos: definição de terreno com a mínima necessidade de desmatamento, evitando assim diagnósticos mais complexos em termos de impactos ambientais, e problemas na liberação com os órgãos ambientais regentes; escolha de área plana e com a mínima quantidade de cinturões verdes ao redor, para evitar assim a proliferação de pragas; localização em zona rural, de preferência distritos industriais, para minimização de problemas relacionados a vizinhança, tais como: 
emissão de poluentes, odores desagradáveis, poluição visual etc.; proximidade a rodovias, facilitando a logística de distribuição de produtos acabados e recebimento da matériaprima; localização estratégica junto aos fornecedores de coco, buscando minimizar os custos inerentes ao transporte, aumentando o tempo de vida útil do coco; estar próxima as linhas de distribuição de gás natural; proximidade a corpos de água, para recepção de efluentes finais, ou mesmo alternativa de consumo industrial e/ou irrigação. Com base no atendimento de todos esses critérios foi realizado o dimensionamento dos valores associados ao custo da aquisição do terreno.

\subsection{Demanda Subterrânea de Água}

O uso de água potável é obrigatório para as finalidades nas indústrias de alimentação, a não ser para a produção de vapor, para a extinção de incêndios ou para refrigeração. Para um processamento de 10 toneladas por dia de coco, a necessidade de água é de cerca de $16 \mathrm{~m}^{3}$ de água por dia. Sendo que cerca de $40 \%$ dessas necessitam de padronização para a classificação de água potável (filtração e desinfecção) e o restante sem a necessidade de tratamentos apenas desinfetantes. Os critérios sanitários devem ser observados, e a estimativa do tempo de vida útil do poço deve ser qualificada para evitar imprevistos operacionais.

\subsection{Demanda de Matéria-prima}

A escolha dos fornecedores é um principal fator, de início, para definição das rotas e rotinas operacionais a serem definidas na operação da indústria. Fatores como o ciclo produtivo do coqueiro e a demanda mensal de produção devem ser observados, afim de que não ocorram problemas com a falta do produto, ou mesmo, oscilações significativas no preço desse. Utilizou-se o fator de segurança “dois", para um período de produção de três meses, tendo um sobressalente que garanta as necessidades da indústria. O coco deve ser adquirido descascado, para evitar assim problemas inerentes a disposição dos resíduos sólidos agregados. 


\section{4. Área física}

O layout definido para a indústria é ilustrado na Figura 1, tendo sido definidas as seguintes seções: armazenamento de coco; almoxarifado; expedição de produtos acabados; casa de máquinas; área de produção; setor administrativo; estação de tratamento de efluentes (ETE); e, estação de captação e tratamento de águas.
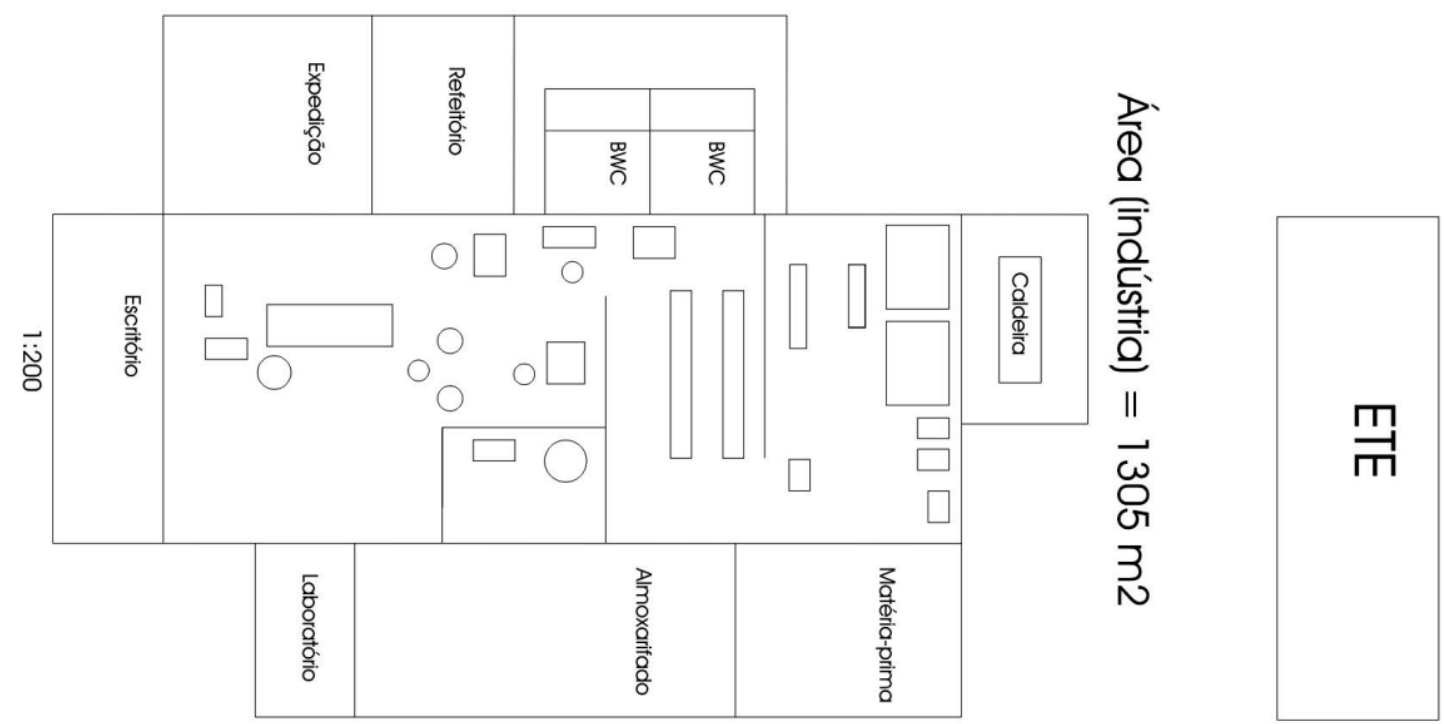

Figura 1 - Layout proposta para o referido projeto.

O coco é um fruto altamente perecível, principalmente quando já retirado de sua casca, com isso o período de armazenamento não é recomendado que seja extenso, pois as perdas com problemas na maturação são bastante onerosas. Contudo, sugere-se como tempo máximo de armazenamento o período de sete dias, tendo uma escolha criteriosa dos fornecedores um papel decisivo. No que diz respeito aos produtos acabados, a logística de venda e distribuição não foi contemplada nas descrições desse projeto, no entanto, na simulação utilizada apresentar-se-á os principais mercados alvos.

\subsection{Planta energética}

A energia elétrica a ser consumida pela indústria é do fornecimento da companhia energética de atendimento público, sendo a diferença de potencial requerido, no sistema trifásico, de $380 \mathrm{~V}$. 
No projeto, em questão, não foi contemplado o orçamento de um gerador de energia a óleo (considerando que o fluxo de operação considerado foi apenas diurno e que a maioria dos equipamentos opera apenas com vapor), no entanto, é uma medida de segurança para não ocorrer problemas no que diz respeito a produtos, com a falta do fornecimento energético.

A demanda de energia térmica é suprida por um sistema de caldeiras com queima de gás natural, ou alternativamente de lenha e cascas de coco. Os vapores gerados são utilizados em todas as etapas que necessitam de aquecimento, tais como: desidratação, pasteurização etc.

\subsection{Tratamento de Resíduos}

Uma das principais conseqüências de um processo industrial está na geração dos subprodutos ou resíduos inerentes ao ciclo produtivo, e isto vem ganhando níveis de significância máxima junto aos órgãos competentes. No ciclo produtivo do coco, os principais resíduos gerados são sólidos e líquidos, sendo praticamente imperceptíveis as emissões gasosas.

Quanto aos resíduos sólidos, os principais são: coco fora de especificação, quengas, película e embalagens danificadas. O tratamento idealizado contempla o reaproveitamento para a formulação de ração dos resíduos orgânicos (com a comercialização desses), a comercialização para o uso na produção de botões, o consumo energético das quengas sobressalentes (ou resíduos dessas) e a comercialização dos resíduos plásticos e vítreos segregados.

No caso dos efluentes líquidos, basicamente constituídos por águas de lavagem e a própria água do coco, estes deve atender aos padrões de emissão para serem dispostos em corpos receptores ou para reaproveitamento na fertirrigação do solo. Os padrões a serem atendidos com o tratamento são regidos pelo CONAMA 430/2011.

$\mathrm{O}$ atendimento desses aspectos legais pode ser obtido por um sistema de tratamento de efluentes, que inclui etapas físicas de remoção de sólidos e gorduras, e degradação microbiológica dos demais constituintes orgânicos. Esse sistema deve ter dimensionamento preciso, com observação de critérios como: segregação dos efluentes, evitando o aumento do grau de complexibilidade do tratamento (tendo efeito direto na definição do sistema de esgotamento); quantificação das vazões geradas, a fim de dimensionar os tempos e vazões ideais de operação do sistema de tratamento; efetuar análises periódicas de avaliação do 
sistema de tratamento; e, proceder à limpeza e a manutenção em níveis freqüentes, a fim de garantir a eficiência do sistema.

\subsection{Fluxo do Processo}

O processo de obtenção do coco desidratado e o leite de coco foram padronizados conforme descrito por Teixeira et al (1985), e adaptado para as inovações tecnológicas disponíveis no mercado atual, nas etapas a seguir:

a) Recepção: nesta etapa, os cocos são pesados e avaliados, e após sua retirada dos caminhões, seguem para os locais de armazenamento. Alguns aspectos como o tempo de detenção, o loteamento e outros critérios higiênicos devem ser observados para atenderem aos menores níveis de perdas possíveis. Para essa etapa se faz necessário o uso de uma balança de uso rodoviário, a fim de acelerar o tempo de recepção e minimizar os gastos com a mão-de-obra e perdas na descarga. A matéria prima a ser utilizada será o coco já descascado, com isso, evita-se os diversos inconvenientes dos resíduos gerados.

b) Classificação e Limpeza: Estas etapas consistem na classificação, pesagem e limpeza dos cocos que seguem para o beneficiamento, como equipamento se faz necessária uma balança de capacidade máxima de 1 tonelada. A classificação é feita de forma visual, no entanto, a seleção é bem falha, devido os danos de interesse estarem presentes na estrutura interna.

c) Cozimento e Retirada da Amêndoa: O coco no seu estado natural apresenta resistência a retirada de sua polpa de forma rápida e seletiva. Esse problema é solucionado pela cocção desse, ainda inteiro, em autoclaves com vapor a alta pressão. Após essa etapa os frutos são serrados e as amêndoas podem ser retiradas de forma manual, com maior facilidade. Os equipamentos envolvidos são: autoclaves, caldeiras de geração de vapor, serras, esteiras e mesa de apoio para a retirada manual.

d) Despeliculagem: Após o processo de retirada das películas, os frutos seguem para a etapa manual de raspagem de da película, frente a uma pedra esmerilhada em rotação contínua. Nesta etapa, o treinamento e a padronização dos operadores são cruciais para um rendimento seletivo e rentável. A película residuária é desidratada e comercializada para 
empresas de extração de óleos ou ração animal. Os equipamentos utilizados consistem em despeliculadores manuais e esteira de distribuição dos frutos.

e) Lavagens: $\mathrm{O}$ endosperma ou polpa despeliculada é submetida a um sistema de lavagem para remoção das sujidades presentes, na primeira etapa o material é imerso em tanques com metabissulfito de sódio, e são removidas as sujidades grosseiras. Numa segunda etapa, esse material é submetido a lavagens por aspersão, para minimizar o consumo de água e ter maiores eficiência na remoção das impurezas. Além dos critérios sanitários, essas lavagens evitam a presença de fragmentos de película, de cor marrom, nos produtos finais. Nessas etapas são necessários tanques de imersão e lavadores por aspersão.

f) Trituração e Prensagem: A polpa é triturada e moída a fim de dar as características finais que se deseja com o coco desidratado, bem como, aumentar a área para extração do leite. Após essa etapa é feita a prensagem, e retirado o leite. O resíduo ainda contendo a maior parte dos constituintes do endosperma, segue para a elaboração do coco ralado, o leite segue para a formulação do leite de coco.

g) Formulação do Leite de coco: Ao leite bruto proveniente da prensa, se adicionam estabilizantes, antioxidantes e conservadores, bem como, água em quantidade suficiente para atingir o nível de $12 \%$ de gordura. Nessa etapa, são coletadas amostras do leite, a fim de definir o nível da formulação. Os aditivos devem ser adicionados a uma temperatura de $80^{\circ} \mathrm{C}$, facilitando a solubilidade desses constituintes.

h) Homogeneização: Após a formulação, o leite ainda apresenta gotículas de gorduras não solubilizadas e alguns fragmentos de sólidos, para emulsificar esses constituintes e aumentar a estabilidade da fase homogênea do produto final, se faz necessário o processo de homogeneização, onde o material é submetido a alta agitação por pistões, oferecendo um produto de alta qualidade.

i) Desaeração: Para obtenção de uma maior estabilidade do produto é necessária a retirada do ar, ainda presente na solução, a fim de minimizar as reações de oxidação. Essa etapa é feita por um desaerador. 
j) Envase: Obtido o produto, segue para o engarrafamento por enchedeira automática (com sistema de fechamento embutido). O envase é feito em garrafas de vidro, e tampadas por rolhas metálicas. Os tamanhos das garrafas são de 200 e $500 \mathrm{~mL}$.

l) Pasteurização: Após envasadas, as garrafas seguem para um túnel de pasteurização onde recebem o tratamento térmico para eliminação dos microorganismos.

m) Rotulagem e Embalagem: Após a pasteurização, as garrafas de leite de coco seguem para receberem seus rótulos, e então serem distribuídas e embaladas em caixas de papelão, para que então possam ser expedidas.

n) Desidratação do Coco: O Bagaço oriundo da etapa de prensagem é disposto em um secador contínuo de leito fluidizado, permanecendo o tempo necessário para atingir níveis de umidade da ordem de $3 \%$. O controle de qualidade é feito mediante análises laboratoriais, a fim de atestar a qualidade do produto e garantir a estabilidade na prateleira.

o) Envase: Após a desidratação, o coco é envasado em embalagens de 50, 100 e 10000 g. Sendo os produtos nobres as embalagens de 50 e $100 \mathrm{~g}$.

p) Laboratório de Análises: No laboratório são realizadas as análises de quantificação do teor de gordura do coco, para definição da diluição necessária para atingir os níveis exigidos (12\%). Bem como, as demais análises do controle de qualidade, a saber: acidez, umidade, $\mathrm{pH}$, sulfitos e sólidos solúveis.

\subsection{Critérios Básicos}

Para o atendimento aos critérios básicos das boas práticas de fabricação (RDC da ANVISA no 45/2010), se faz necessária a segregação das etapas envolvidas nesse processo, essa separação é definida, conforme citado anteriormente, em duas seções: área suja e área limpa.

Essas duas seções devem estar divididas fisicamente por meio de paredes fechadas, a fim de evitar contaminações cruzadas entre as duas etapas, prejudicando a qualidade do produto final. 
Nas etapas que envolvem práticas manuais, deve-se observar um fator preponderante: "a conscientização dos operadores". Existem diversas ferramentas disponíveis para a obtenção de padrões de qualidade nesse sentido, entre essas: sensibilização para a importância da higiene pessoal; capacitação para manipuladores de alimentos, em termos sanitários; técnicas e critérios para a higienização de equipamentos.

Fora do âmbito de pessoal, algumas importantes medidas no âmbito operacional recaem nos seguintes modelos: controle integrado de pragas e normalização da obra civil, evitando: pontos de difícil remoção de sujidades, locais de acúmulo, pisos e esquadrias apropriadas etc.

\subsection{Balanço de Massa do Processo}

Definido o processo produtivo, pôde-se fazer algumas estimativas em termos das perdas envolvidas com o processamento do coco, mediante avaliação experimental e obtenção de dados empíricos de empresas visitadas e descritos na literatura específica, tendo sido definido o seguinte balanço material para o processo, conforme Tabela 1.

Tabela 1: Balanço Material do Processo

\begin{tabular}{|cc|}
\hline & Massa (kg) \\
\hline Matéria-prima & 100,00 \\
\hline Recepção/seleção & 99,00 \\
\hline Cozimento & 98,01 \\
\hline Quebra & 93,11 \\
\hline (endosperma + película) & 39,71 \\
\hline Água de coco & 22,27 \\
\hline Quenga & 30,73 \\
\hline Polpa Fina & 38,52 \\
\hline Descarte de Película & 1,19 \\
\hline Pré-lavagem/Lavagem & 38,02 \\
\hline Trituração & 37,64 \\
\hline Leite Extraído & 18,82 \\
\hline Leite Formulado & 65,92 \\
\hline Perdas no envase do Leite & 0,66 \\
\hline Leite de Coco produzido & 65,26 \\
\hline Coco Úmido & 18,82 \\
\hline Coco Desidratado & 9,79 \\
\hline Perdas no envase do ralado & 0,49 \\
\hline Coco desidratado Final & 9,30 \\
\hline
\end{tabular}




\subsection{Regime de Produção}

Para dimensionamento dos custos operacionais, o regime de produção foi padronizado, conforme segue:

$1^{\text {a }}$ Hora: 5h00: Início da operação das atividades de geração de vapor para dar suporte, em especial, a etapa do cozimento do coco (autoclaves). Na etapa de geração de vapor é colocado o combustível e tem-se início o aquecimento do equipamento e a injeção de água para produção do vapor superaquecido.

$2^{\text {a }}$ Hora: 6h00: É dada a partida para a etapa de cozimento do coco, demandando o coco cozido para as demais etapas do processo de produção. Em seguida, se procede ao início da etapa de corte dos frutos.

$3^{\mathrm{a}}$ Hora: 7h00: Nessa hora é dada continuidade à fase de corte dos cocos cozidos, e procede-se o início da retirada manual da polpa, dando vazão as demais etapas do processo produtivo.

$4^{\mathrm{a}}$ Hora: 8h00: Todas as demais etapas do processo são iniciadas. Tendo início no despeliculamento, seguindo das lavagens e entrando no regime de refino do coco. A etapa de prensagem se procede até que o tanque de recepção atinja o volume de formulação a ser utilizado nas etapas posteriores. Portanto, nos 20 minutos iniciais as demais etapas do processo estão em regime de ajustes e à espera do produto final.

$\mathrm{Na}$ seqüência, tem-se a formulação do leite e a desidratação do coco ralado de forma contínua até a última batelada.

Nas Demais horas: O fluxo operacional segue de forma linear até a última hora de operação, obedecendo a ordem de término das atividades conforme o seu respectivo início, com exceção da geração de vapor que segue de forma interrupta.

Alternativa do regime: A minimização da perda com o aquecimento do startup da caldeira, bem como, a diminuição do número de paralisações dos equipamentos e lavagens desses, podem ser alcançadas com o aumento do número de turnos na indústria. Esse aumento reflete apenas no acréscimo dos custos operacionais e folha de pagamento, aumentando a eficiência de utilização da planta instalada.

\section{METODOLOGIA}

Com base nas premissas adotadas procedeu-se o desenvolvimento do estudo de viabilidade econômica, seguindo a metodologia sugerida por Casarotto Filho; Kopittke 
(2010), variando-se as condições operacionais de forma a obter a sensibilidade dos modelos.

Segundo Casarotto Filho; Kopittke (2010) a definição dos principais indicadores utilizados nesse trabalho, seguem como: Valor Presente Líquido (VPL) é a de uma soma algébrica de fluxos de caixa descontados para o instante presente, a uma taxa de juros i. $\mathrm{O}$ conceito de Taxa Mínima de Atratividade (TMA) como "a taxa mínima de retorno que o investidor pretende conseguir como rendimento ao realizar algum investimento".

A Taxa Interna de Retorno (TIR) é um índice que indica a rentabilidade de um investimento por uma unidade de tempo. Esta representa a taxa de juros compostos que irá retornar o VPL de um investimento com valor 0 (zero). E por fim, o Payback é um indicador que determina o prazo de recuperação de um investimento, também chamado de payout. Este indicador é utilizado para avaliar a atratividade de um investimento, não devendo ser o único considerado como afirmam considerando que "deve ser encarado com reservas, apenas como um indicador, não servindo de seleção entre alternativas de investimento".

Esta análise foi elaborada segundo diversos enfoques, revertendo-se em vários indicadores que demonstram a viabilidade ou não de cada investimento.

Indicadores como Valor Presente Líquido (VPL), Taxa Interna de Retorno (TIR) e Payback Descontado são utilizados nestas análises, visando, demonstrar a viabilidade de um único investimento ou, através da comparação, demonstrar qual entre dois ou mais investimentos será o de melhor retorno ou de retorno mais rápido. As equações (1) e (2), conforme Samanez (2002) representam o cálculo do VPL e TIR.

$$
\begin{gathered}
\mathrm{VPL}=F C_{1}+\frac{F C_{2}}{(1+i)^{j+1}}+\frac{F C_{3}}{(1+i)^{j+2}}+\ldots \frac{F C_{6}}{(1+i)^{j+5}} \\
V P L=0=\text { Investimento Inicial }+\sum_{t=1}^{N} \frac{F_{t}}{(1+T I R)^{t}}
\end{gathered}
$$

Onde:

FC: Fluxo de caixa

i: taxa de juros (mínima de atratividade)

j: ano

Ft: fluxo de caixa total 
Para efeito de conversão das moedas foi considerada uma razão de 1:2, entre o dólar americano e a moeda brasileira.

$\mathrm{Na}$ estimativa do capital de giro necessário foi adotado o valor aproximado de 3 vezes o somatório da folha de pagamento e custos fixos do empreendimento; o que daria uma autonomia de três meses de atividades.

A análise de sensibilidade foi realizada mediante a determinação das variáveis de retorno econômico para diferentes percentuais da capacidade nominal das plantas instaladas, ou seja, simulando cenários do mercado quanto a demanda pelos referidos produtos.

\section{RESULTADOS E DISCUSSÕES}

Considerando a metodologia descrita anteriormente procedeu-se o levantamento das variáveis que compõe o estudo de viabilidade técnica e econômica, a saber: investimentos, custos, receitas e fluxos de caixa. Bem como, realizou-se as simulações para os valores obtidos.

\subsection{Premissas do Estudo}

Após criteriosa avaliação do processo produtivo, foram levantados junto aos principais representantes do Brasil, os equipamentos necessários para a implantação da unidade de produção. Essas estimativas foram dimensionadas para capacidades de 7 e 14 toneladas (padrão para 6 dos fornecedores pesquisados), a fim de avaliar a rentabilidade dos investimentos. Visto que, o processo de beneficiamento de coco, devido a grande necessidade de energia térmica, não favorece unidades de baixa produção, além do mercado ser seletivo a grandes marcas e a padrões de qualidade altamente criteriosos.

Os equipamentos necessários a implantação, respectivamente, para as unidades de 7 e 14 toneladas envolvem investimentos de U\$ 1,4 e 1,8 milhões. Logo, foi observado que o investimento inicial não obedece a uma relação linear, e que a duplicação da capacidade não segue necessariamente de uma duplicação nos custos de implantação.

Os valores apresentados correspondem a uma média das cotações realizadas, mediante seleção aleatória e considerando os mesmos padrões de qualidade.

Em termos de obra civil, não há distinção significativa nas áreas das duas unidades de produção, devido a ampliação que segue aos equipamentos serem unicamente em 
caráter vertical, com algumas exceções horizontais, não repercutindo em diferenças no custo global da unidade de produção.

A área total, incluindo a caixa dágua de abastecimento, bem como a Estação de Tratamento de Efluentes (ETE), foi orçada em U\$ 600 mil, tendo a estrutura do galpão adequada às normas vigentes, em termos sanitários.

O investimento para o abastecimento de água ao processo é inicialmente calculado pela perfuração de um poço, com cerca de 60 metros, tendo sido orçado em U\$ 180,00/m. Representando um custo de U\$10,8 mil, requisitando de outros acessórios que totalizam um investimento da ordem de U\$15 mil.

O laboratório foi orçado, de acordo com a demanda de análises que se tem no processo produtivo e no controle de qualidade, necessitando cerca de U\$ 22 mil em investimentos.

Em termos operacionais foram levantados os custos dos principais insumos e materiais envolvidos no processo, e os gastos com energia e demais elementos inerentes ao processo. Na Tabela 2, são mostrados os custos atuais para os principais insumos necessários ao processo.

Tabela 2: Custos dos Insumos

\begin{tabular}{|c|c|c|}
\hline INSUMOS & \multicolumn{2}{|c|}{ VALOR UNITÁRIO } \\
\hline Coco in natura (kg) & U\$ & 0,70 \\
\hline Garrafa 200 (und) & U\$ & 0,19 \\
\hline Garrafa 500 (und) & $\mathrm{U \$}$ & 0,27 \\
\hline Tampas (und) & U\$ & 0,02 \\
\hline Rotulo (und) & U\$ & 0,02 \\
\hline Caixa 200 (und) & $\mathrm{U \$}$ & 0,65 \\
\hline Caixa 500 (und) & U\$ & 0,59 \\
\hline Saco papel (und) & $\mathrm{U \$}$ & 0,30 \\
\hline Saco plast. (und) & U\$ & 0,26 \\
\hline Cx.c ralado $50 \mathrm{~g}$ (und) & U\$ & 0,61 \\
\hline Cx.c ralado 100g (und) & U\$ & 0,65 \\
\hline Saquinho 50 g (und) & $\mathrm{U \$}$ & 0,03 \\
\hline Saquinho $100 \mathrm{~g}$ (und) & $\mathrm{U \$}$ & 0,05 \\
\hline Metabissulfito de sódio (kg) & $\mathrm{U \$}$ & 2,20 \\
\hline Benzoato de sódio (kg) & $\mathrm{U \$}$ & 6,00 \\
\hline Carboximetilcelulose (kg) & U\$ & 30,00 \\
\hline Ác. Cítrico (kg) & U\$ & 3,90 \\
\hline Goma guar (kg) & $\mathrm{U \$}$ & 11,64 \\
\hline $\begin{array}{l}\text { Produtos Químicos de tratamento de } \\
\text { água e efluentes }\left(\mathrm{kg} / 100 \mathrm{~m}^{3} \text { água }\right)\end{array}$ & U\$ & 15,53 \\
\hline Fita da adesiva $(\mathrm{m})$ & $\mathrm{U \$}$ & 0,03 \\
\hline $\begin{array}{c}\text { Operação do Sistema de Tratamento } \\
\text { de efluente }\left(\mathrm{U} \$ \mathrm{~m}^{3}\right)\end{array}$ & U\$ & 0,01 \\
\hline $\begin{array}{c}\text { Operação do Sistema de Tratamento } \\
\text { da água }\left(\mathrm{U} \$ / \mathrm{m}^{3}\right)\end{array}$ & U\$ & 0,00038 \\
\hline Gás natural $\left(\mathbf{m}^{3}\right)$ & $\mathrm{U \$}$ & 0,54 \\
\hline Manutenção Mensal & U\$ & $2.000,00$ \\
\hline
\end{tabular}


Em termos do quadro funcional, a folha de pagamento da empresa foi estimada e, é descrita na Tabela 3.

Tabela 3: Folhas de Pagamento

\begin{tabular}{|c|c|c|c|}
\hline FUNÇÃO & $\mathrm{N}^{0}$ Func. (7) & $\mathbf{N}^{0}$ Func. (14) & SALÁRIO (U\$) \\
\hline VIGILANTE & 4 & 4 & 700 \\
\hline COZIMENTO & 2 & 3 & 400 \\
\hline SERRA & 1 & 1 & 400 \\
\hline TIRAGEM & 8 & 16 & 400 \\
\hline DESPELICULAGEM & 15 & 30 & 400 \\
\hline OPERADOR PRENSA & 1 & 1 & 500 \\
\hline SECAGEM DO COCO & 2 & 2 & 500 \\
\hline FORMULAÇÃO/TÉCNICO & 1 & 2 & 500 \\
\hline ENCHEDORA/TAMPADORA & 1 & 1 & 500 \\
\hline TRATAMENTO TÉRMICO & 1 & 1 & 500 \\
\hline ROTULADORA & 1 & 1 & 500 \\
\hline EMBALAGEM (RALADO) & 1 & 1 & 500 \\
\hline CAIXA LEITE & 3 & 6 & 400 \\
\hline CAIXA RALADO & 2 & 3 & 400 \\
\hline ENCARREGADO & 2 & 2 & 600 \\
\hline CALDEIRISTA & 2 & 2 & 900 \\
\hline LIMPEZA & 2 & 2 & 400 \\
\hline JARDIM/MANUTENÇAO ETE & 1 & 1 & 400 \\
\hline $\begin{array}{l}\text { CONTADOR } \\
\end{array}$ & 1 & 1 & 1600 \\
\hline AUXILIAR ADMINISTRATIVO & 1 & 1 & 600 \\
\hline GERENTE DE VENDAS & 1 & 1 & 2000 \\
\hline RESPONSÁVEL TÉCNICO & 1 & 1 & 3400 \\
\hline MANUTENÇÃO GERAL & 2 & 2 & 1000 \\
\hline Salários & 56 & 85 & \\
\hline Encargos Trabalhistas & & & $80 \%$ \\
\hline Horas-extras & & & Já inclusas \\
\hline
\end{tabular}

As análises físico-químicas de controle de qualidade e de processo foram estimadas pelos custos individuais de seus componentes, apresentando os valores médios de expressos na Tabela 4.

Tabela 4: Folhas de Pagamento

\begin{tabular}{|cc|}
\hline ANÁLISE & CUSTO POR AMOSTRA (U\$) \\
\hline GORDURAS & 0,15 \\
\hline ACIDEZ & 3,69 \\
\hline SO $_{2}$ & 0,25 \\
\hline UMIDADE & 0,38 \\
\hline PH & 0,10 \\
\hline
\end{tabular}


Os custos com energia foram estimados pela equação do gráfico abaixo:

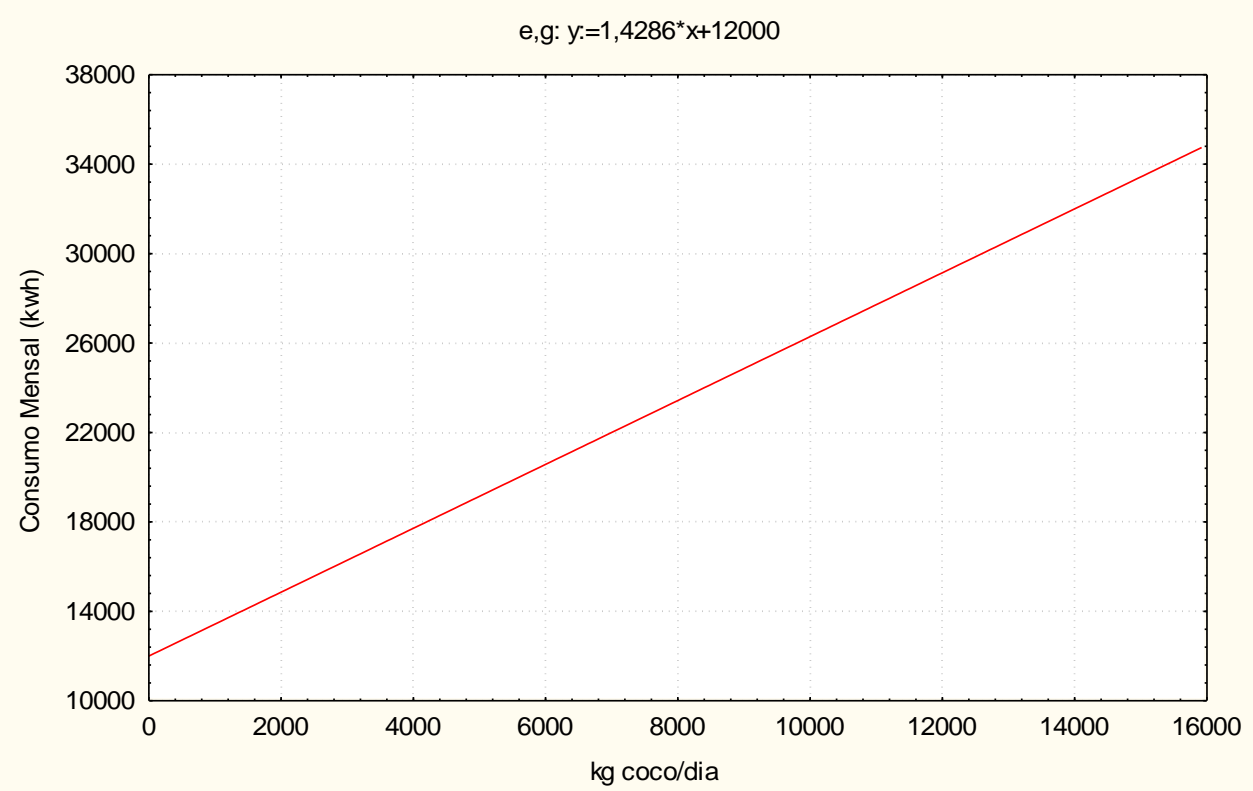

Figura 2 - Relação consumo energético em função da produção.

O consumo de gás natural é dado pelos fabricantes das caldeiras e foi utilizado assim na simulação dos custos operacionais.

Os custos originados de despesas com fretes foram calculados mediante estimativa feita para os principais mercados consumidores dos produtos (as comissões de vendas foram incluídas com um porcentual de 3\%), e seguem do modelo da Tabela 5.

Tabela 5: Custos Unitários com Frete

\begin{tabular}{|cc|}
\hline FRETE & PESO/CX (KG) \\
\hline CAIXA 200ML & 7,5 \\
\hline CAIXA 500ML & 8,8 \\
\hline CAIXA DE COCO RAL. 200ML & 3,2 \\
\hline CAIXA DE COCO RAL. 200ML & 3 \\
\hline SACO 10KG & 10,3 \\
\hline DISTRIBUIÇÃO DAS CARGAS/ \% \\
\hline NORDESTE & $50 \%$ \\
\hline SUDESTE & $35 \%$ \\
\hline SUL & $5 \%$ \\
\hline CENTRO OESTE & $5 \%$ \\
\hline NORTE & $5 \%$ \\
\hline
\end{tabular}

Os valores de venda dos produtos foram obtidos em contatos diretos com os representantes e indústrias locais e regionais. Tendo como valores médios os dados da Tabela 6. 
Tabela 6: Custos Unitários com Frete

\begin{tabular}{|cc|}
\hline PRODUTOS & PREÇO VENDAS/CX. U\$ \\
\hline LEITE DE COCO 200 mL & 22,00 \\
\hline LEITE DE COCO 500 $\mathrm{mL}$ & 27,00 \\
\hline COCO RALADO 50 g & 37,00 \\
\hline COCO RALADO 100 g & 26,75 \\
\hline COCO RALADO $10 \mathrm{~kg}$ & 70,00 \\
\hline & \\
\hline SUBPRODUTOS & PREÇO VENDAS /KG. U\$ \\
\hline CASCA VENDIDA & 0,30 \\
\hline 30\% PRODUZIDA & 0,40 \\
\hline PELÍCULA 2\% & \\
\hline
\end{tabular}

A divisão feita dos produtos a serem produzidos foi realizada mediante conhecimento do mercado consumidor, e a tendência que é observada para o consumo do leite de coco. Na avaliação de mercado, observou-se que cerca de $80 \%$ do leite de coco consumido é padronizado para um teor de gordura de $12 \%$, sendo assim a projeção inicial realizada compreendendo unicamente essa produção. Em termos do coco ralado foi observado que o alto valor agregado e a maior procura é vista nas embalagens comercializadas no mercado varejista, ou melhor, 50 e $100 \mathrm{~g}$ (justificando o direcionamento para esse mercado), entretanto, um trabalho de divulgação e marketing deve ser trabalhado para a consolidação da marca no mercado consumidor, e garantir a lucratividade da empresa.

\subsection{Simulação Econômica}

A partir dos dados obtidos, e mostrados nas Tabelas 7 e 8, elaborou-se uma planilha eletrônica onde foram simuladas frações da capacidade total de produção, obtendo os custos e receitas totais, a fim de determinar o ponto de equilíbrio (custo = receita) da empresa. Para efeito dos cenários de avaliação econômica foram calculados os custos variáveis, fixos, custo total, receita total e o valor do investimento inicial.

Os projetos seguiram para duas estruturas, considerando um processamento de 7000 e $14000 \mathrm{~kg} / 8 \mathrm{~h}$. As simulações da sensibilidade foram desenvolvidas considerando os diferentes níveis de produção, que envolvem da capacidade mínima a máxima da estrutura nominal projetada. 
Tabela 7: Custos Unitários com Frete

\begin{tabular}{|c|c|c|}
\hline \multicolumn{3}{|l|}{$\begin{array}{c}\text { AVALIAÇÃO GLOBAL } \\
7000 \text { KG/8 h }\end{array}$} \\
\hline \multicolumn{3}{|l|}{ Custo Variável } \\
\hline Despesas Fiscais & $\mathrm{U \$}$ & $140.810,37$ \\
\hline Frete, Seguros etc & U\$ & $28.688,20$ \\
\hline Comissões & U\$ & $15.744,12$ \\
\hline Energia/Água & U\$ & $5.060,05$ \\
\hline Custo Operacional (incluindo salário - corpo operacional) & U\$ & $273.547,15$ \\
\hline Serviços de Terceiros & U\$ & $1.000,00$ \\
\hline Custo Total Variável & U\$ & $464.849,89$ \\
\hline \multicolumn{3}{|l|}{ Custos Fixos } \\
\hline Folha de Pagamento (Setor Administrativo - Despesas) & U\$ & $17.880,00$ \\
\hline Custos Administrativos (telefone, expediente etc) & U\$ & $1.500,00$ \\
\hline Diversos & U\$ & $1.000,00$ \\
\hline Depreciação (Equipamentos, Construções etc) & U\$ & $13.794,18$ \\
\hline Custo Fixo Total & U\$ & $34.174,18$ \\
\hline \multicolumn{3}{|l|}{ Custo Total } \\
\hline Custo Total & U\$ & $499.024,06$ \\
\hline \multicolumn{3}{|l|}{ Receita Total } \\
\hline Receita Total & U\$ & $800.000,00$ \\
\hline \multicolumn{3}{|l|}{ Investimento Inicial } \\
\hline Poço Tubular & U\$ & $10.800,00$ \\
\hline Projeto ETE & U\$ & $6.000,00$ \\
\hline Obra Civil + ETE & U\$ & $600.000,00$ \\
\hline Projeto Civil & U\$ & $12.000,00$ \\
\hline Legalização da Empresa & U\$ & $5.000,00$ \\
\hline Projeto de Processos & U\$ & $25.000,00$ \\
\hline Treinamento de Pessoal & U\$ & $5.000,00$ \\
\hline Instalação do Laboratório & U\$ & $22.000,00$ \\
\hline Custo de Instalação dos Equipamentos & U\$ & $50.000,00$ \\
\hline Equipamentos & U\$ & $1.338 .901,20$ \\
\hline Capital de Giro & U\$ & $200.000,00$ \\
\hline TOTAL & U\$ & $2.263 .901,20$ \\
\hline
\end{tabular}


Tabela 8: Custos Unitários com Frete

\begin{tabular}{|c|c|c|}
\hline \multicolumn{3}{|l|}{$\begin{array}{c}\text { AVALIAÇÃO GLOBAL } \\
14000 \mathrm{KG} / 8 \mathrm{~h}\end{array}$} \\
\hline \multicolumn{3}{|l|}{ Custo Variável } \\
\hline Despesas Fiscais & U\$ & $281.620,73$ \\
\hline Frete, Seguros etc & U\$ & $57.376,41$ \\
\hline Comissões & U\$ & $31.488,23$ \\
\hline Energia/Água & U\$ & $7.360,09$ \\
\hline Custo Operacional (incluindo salário - corpo operacional) & U\$ & $543.351,56$ \\
\hline Serviços de Terceiros & U\$ & $1.000,00$ \\
\hline Custo Total Variável & U\$ & $922.197,02$ \\
\hline \multicolumn{3}{|l|}{$\begin{array}{l}\text { Custos Fixos } \\
\end{array}$} \\
\hline Folha de Pagamento (Setor Administrativo - Despesas) & $\mathrm{U} \$$ & $17.880,00$ \\
\hline Custos Administrativos (telefone, expediente etc) & U\$ & $1.500,00$ \\
\hline Diversos & U\$ & $1.000,00$ \\
\hline Depreciação & U\$ & $26.737,19$ \\
\hline Custo Fixo Total & U\$ & $47.117,19$ \\
\hline \multicolumn{3}{|l|}{ Custo Total } \\
\hline Custo Total & U\$ & $969.314,21$ \\
\hline \multicolumn{3}{|l|}{ Receita Total } \\
\hline Receita Total & U\$ & $1.600 .000,00$ \\
\hline \multicolumn{3}{|l|}{ Investimento Inicial } \\
\hline Poço Tubular & U\$ & $10.800,00$ \\
\hline Projeto ETE & U\$ & $6.000,00$ \\
\hline Obra Civil + ETE & U\$ & $600.000,00$ \\
\hline Projeto Civil & U\$ & $12.000,00$ \\
\hline Legalização da Empresa & $\mathrm{U \$}$ & $5.000,00$ \\
\hline Projeto de Processos & U\$ & $25.000,00$ \\
\hline Treinamento de Pessoal & U\$ & $5.000,00$ \\
\hline Instalação do Laboratório & U\$ & $22.000,00$ \\
\hline Custo de Instalação dos Equipamentos & U\$ & $50.000,00$ \\
\hline Equipamentos & U\$ & $1.867 .062,60$ \\
\hline Capital de Giro & U\$ & $300.000,00$ \\
\hline TOTAL & U\$ & $2.892 .062,60$ \\
\hline
\end{tabular}

Considerando as premissas adotadas nas Tabelas 7 e 8, foram realizados os desenvolvimentos das relações entre custo e receita total para determinação do ponto de equilíbrio dos investimentos, definindo as faixas de variação para o estudo de sensibilidade. Os resultados das simulações são mostrados nas Figuras 3 e 4. 


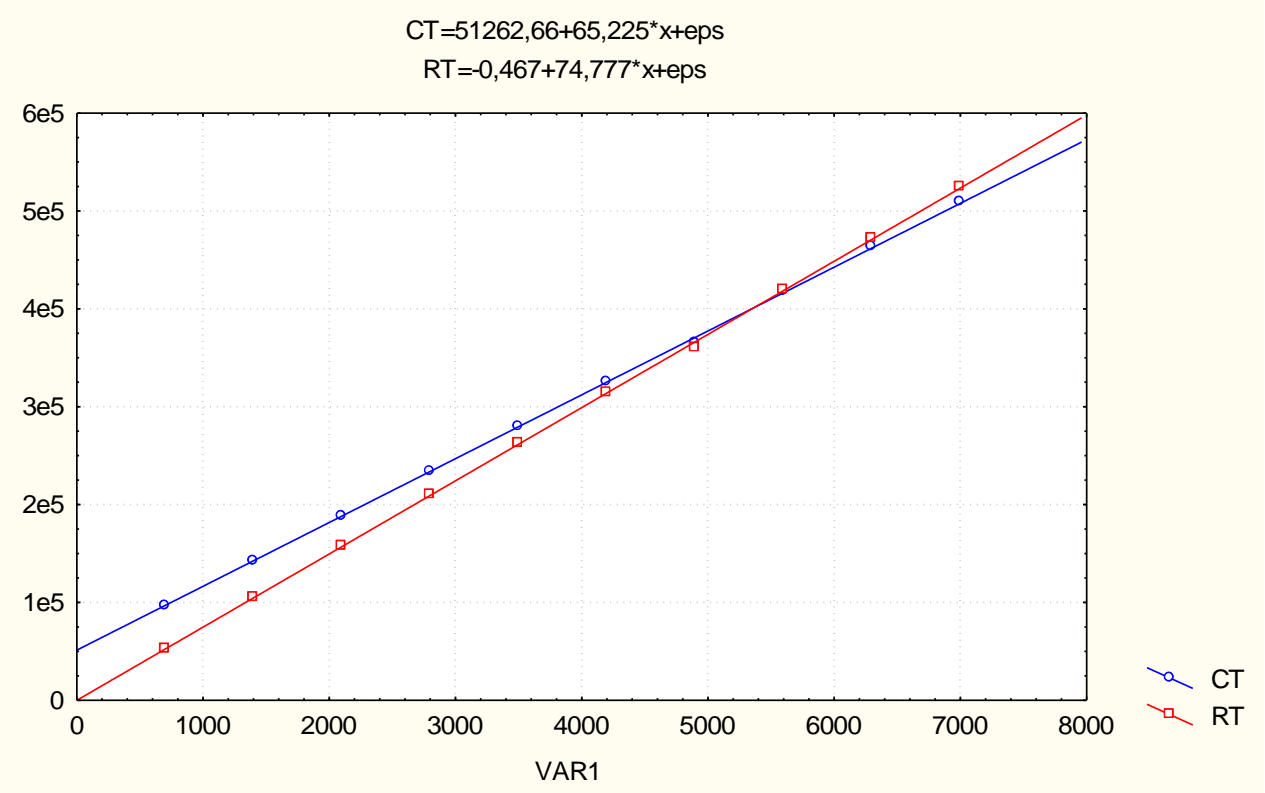

Figura 3 - Custo (CT) e receita total (RT) em função da produção (VAR1 - kg de coco) para a estrutura dimensionada de $7000 \mathrm{~kg} / 8 \mathrm{~h}$.

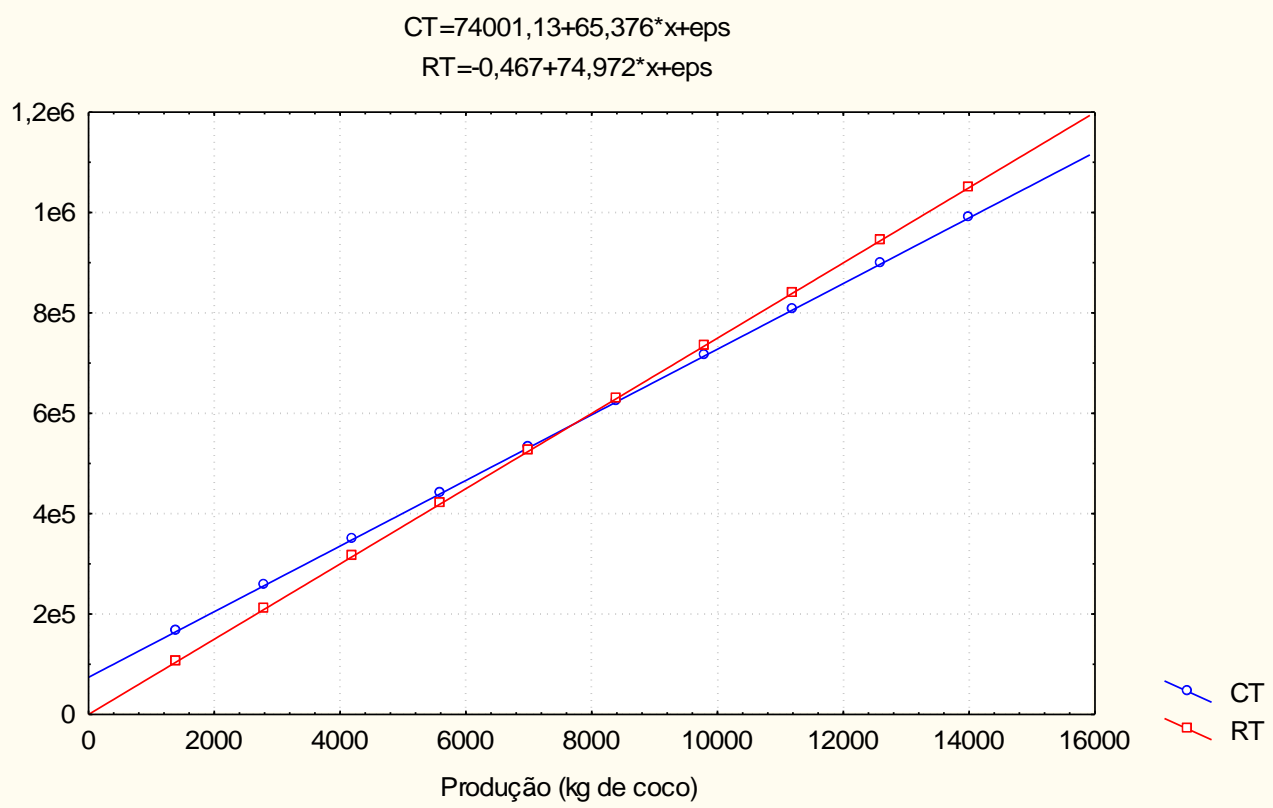

Figura 4 - Custo (CT) e receita total (RT) em função da produção (kg de coco) para a estrutura dimensionada de $14000 \mathrm{~kg} / 8 \mathrm{~h}$.

Da regressão linear dos dados foi possível a obtenção dos modelos lineares, que foram considerados para as simulações de custos e receitas, em função da capacidade de produção das instalações. 
Considerando os mesmos valores foi avaliado o desempenho para o lucro liquido operacional (EBITDA), sem a influência da carga tributária associada. Observando-se que os pontos de equilíbrio na Figura 5.

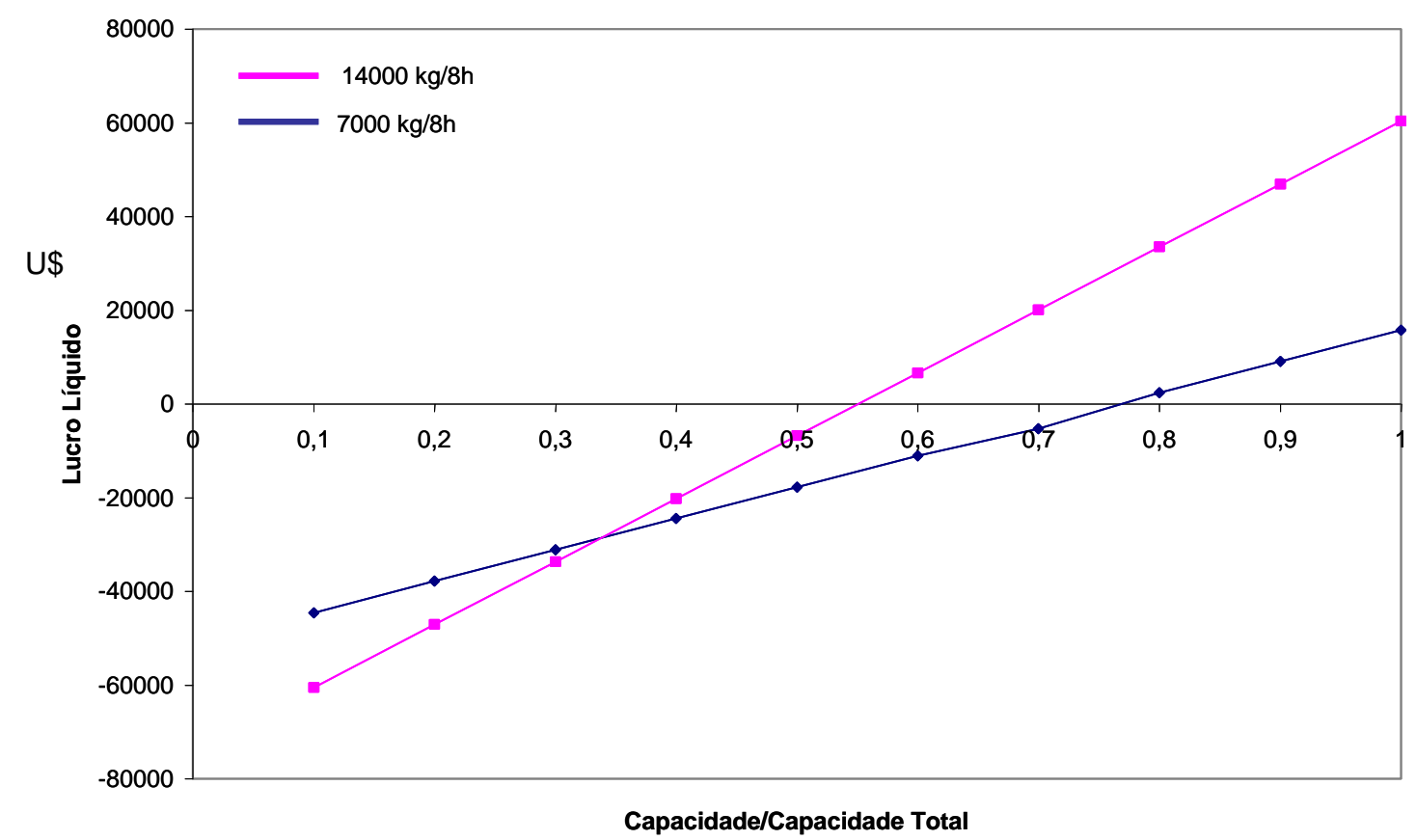

Figura 5 - Lucro operacional em função da produção.

Em termos globais, os resultados com as simulações para os investimentos apresentaram pontos de equilíbrios de 78 e 55\%, para as capacidades de 7 e 14 mil quilos de produto por dia. Demonstrando que a estrutura dimensionada em pequenas cargas de produção tem maior dificuldade no rateio dos custos fixos associados, em especial, pelo forte impacto das variáveis que envolvem adequações sanitárias, controle da qualidade e cumprimento de legislação ambiental.

\subsection{Indicadores Econômicos}

Considerando os pontos de equilíbrio foram realizadas as analises de sensibilidade para o VPL, TIR e payback a partir do ponto de equilíbrio até a capacidade nominal da estrutura. Para efeito das simulações a taxa mínima de atratividade (TMA) foi considerada como sendo 10\%. Nas Figuras 6, e 7 são apresentados os resultados obtidos para as diferentes simulações. 


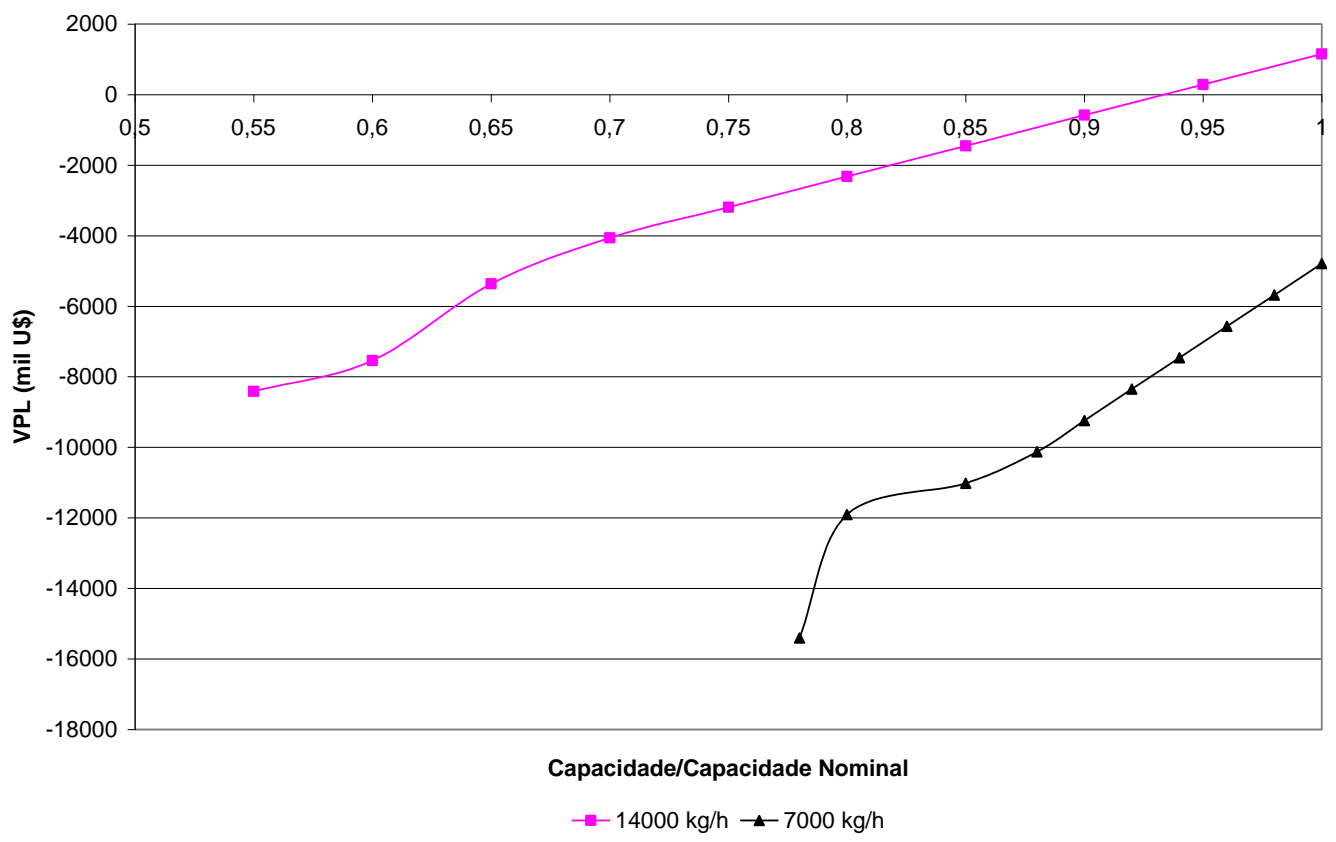

Figura 6 - Análise de sensibilidade do VPL em função da produção.

Observa-se na Figura 6 que para o caso de 7000 kg/h o investimento não apresenta VPL positivo, mesmo considerando $100 \%$ da capacidade nominal. Em relação a capacidade de $14000 \mathrm{~kg} / 8 \mathrm{~h}$, mesmo tendo-se um ponto de equilíbrio de 50\% o VPL só torna-se positivo após $95 \%$ da capacidade produtiva.

Em relação a taxa interna de retorno (TIR) o comportamento é semelhante, entretanto, torna-se positivo acima de $98 \%$ da capacidade produtiva. Observa-se da análise conjugada, que a utilização desses parâmetros pode levar a falhas na interpretação do EVTE, visto que os cenários de $100 \%$ de operação da capacidade nominal são cenários complexos em termos de mercado.

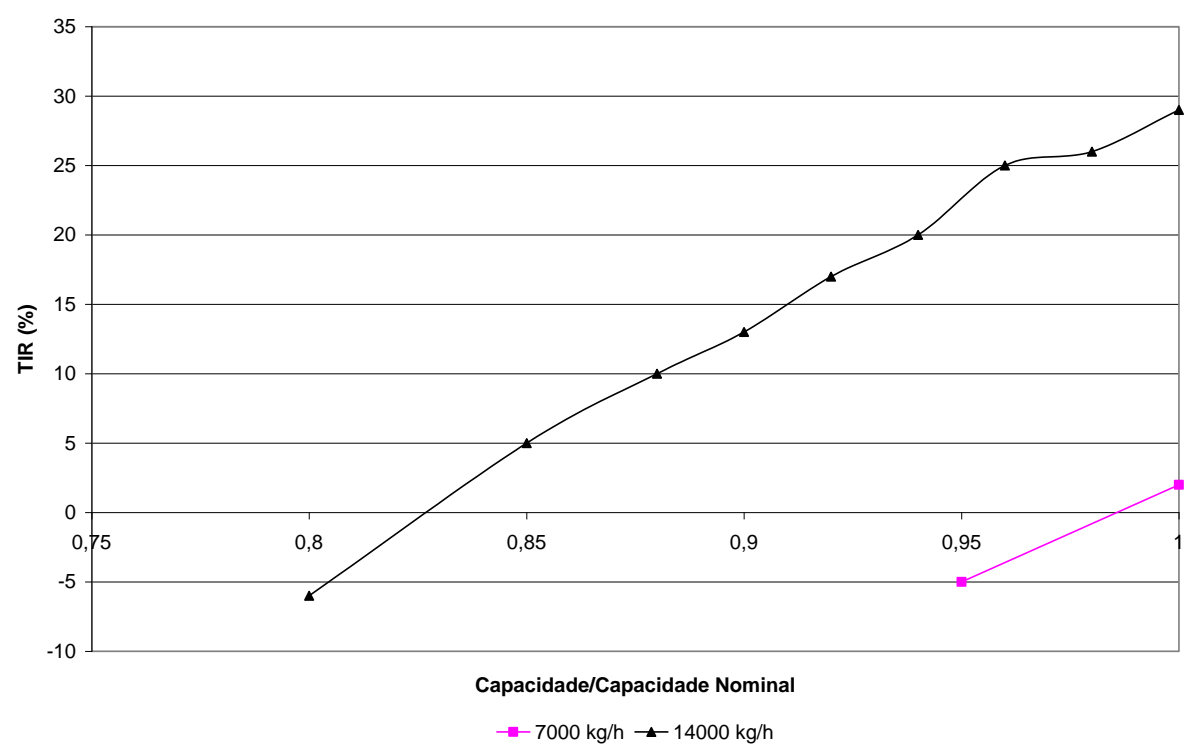

Figura 7 - Análise de sensibilidade do TIR em função da produção. 
A análise do payback é similar aos períodos do ponto de equilíbrio, tendo-se os cenários representados na Figura 8, tendo-se 4,8 e 5,8 anos de tempo de retorno para as capacidades de 7000 e $14000 \mathrm{~kg} / 8 \mathrm{~h}$, respectivamente.

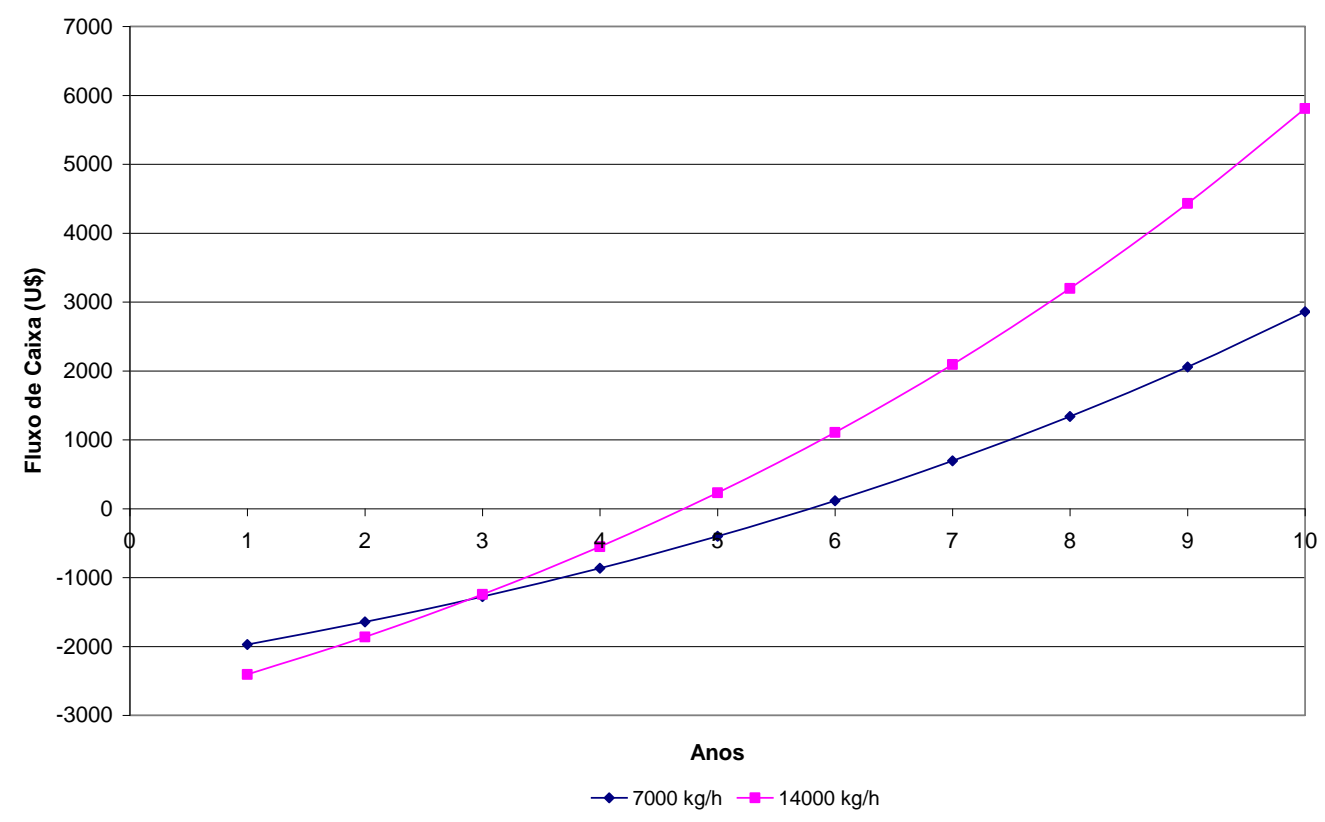

Figura 7 - Determinação do payback nos casos simulados.

\subsection{Análise de Mercado (Demanda)}

Segundo EMBRAPA (2011) o mercado dos produtos industrializados de coco (desidratado ou leite de coco) possui uma grande demanda no mercado interno, sendo necessários índices elevados de importação ( $22 \%$ da produção interna) para suprir a indústria secundária que utiliza de tais produtos como insumos, a saber: sorvete, doces, biscoitos etc. Logo, a instalação de unidades produtivas com fluxo de $14000 \mathrm{~kg}$ por dia é assimilada facilmente pelo mercado, visto que tal volume corresponde a índices inferiores a $3 \%$ do volume importado.

\section{CONCLUSÕES}

Em termos técnicos foi observado que o investimento apresenta maior atratividade com uma capacidade de produção ampliada, sendo assim a quantidade estimada de 14000 $\mathrm{kg} /$ dia a recomendada para a implantação da empresa. Podendo se trabalhar com frações superiores a $7700 \mathrm{~kg} / \mathrm{dia}$ e ainda obter lucro com o processo. Além disso, o projeto inclui 
fatores de segurança que dão margem a certeza da utilização da capacidade máxima da unidade. Entretanto, o valor presente líquido só tem viabilidade com índices superiores a 95\% da capacidade de produção, o que limita e deixa o empreendimento bastante susceptível as flutuações de mercado, preço e novos investimentos impostos por legislações específicas.

$\mathrm{Na}$ análise do valor presente líquido (VPL), ainda, observou-se, para uma taxa mínima de atratividade de $10 \%$, que o empreendimento com capacidade nominal de 7000 kg/dia, não apresenta valores positivos para este parâmetro econômico. Apesar do payback ser inferior a vida útil das instalações e que a TIR ter valores acima de zero para $98 \%$ da capacidade nominal. Sendo assim, considera-se tal investimento como inviável.

A análise de sensibilidade permitiu uma avaliação mais rigorosa, gerando uma interpretação mais precisa dos riscos associados, em especial, na capacidade de produção mínima para realização dos resultados econômicos projetados.

Outra alternativa, para maximizar os resultados econômicos desta estrutura é o regime contínuo de operação, já que todos os parâmetros mostrados foram para um ciclo de produção em apenas um turno, com a alternativa de ampliação rentável. Considerando as perspectivas de demanda do mercado citada por EMBRAPA (2011) a absorção pelo mercado não seria o impeditivo, visto que existe a necessidade de importação; porém, deve-se envolver uma boa estratégia comercial para atender a tais fluxos e cadeia de relacionamento.

É importante a observação dos aspectos legais e sanitários citados no projeto, a fim de adequar a empresa às exigências do mercado consumidor, em especial, para a rotulagem de marcas já comerciais. Em termos ambientais, essas limitações são direcionadas unicamente para a liberação da atividade, porém, foram itens considerados representativos no investimento inicial. E que estes requisitos são bastante impactantes nos custos e investimentos do referido modelo estudado. Na prática, o descumprimento destes requisitos torna a maioria dos empreendimentos mais competitivos, porém, a base de crimes ambientais, baixo padrão de qualidade e estratégias errôneas pelo ponto de vista tributário e/ou trabalhista; o que torna tal prática não recomendada e de alto risco.

A implantação do projeto requer que o mercado consumidor seja estudado de modo a que se conheça seu perfil, em termos de sexo, classe social, nível de instrução, faixa etária, altura e peso, a fim de projetar o sistema de marketing e área de atuação da empresa. 


\section{REFERÊNCIAS}

ANVISA. Resolução - RDC $\mathbf{n}^{\mathbf{0}}$ 45, de 3 de novembro de 2010. Dispõe sobre aditivos alimentares autorizados para uso segundo as Boas Práticas de Fabricação (BPF).

BALARINE, O. Administração e Finanças para Construtores e Incorporadores. Porto Alegre, Edipucrs, 1996. 196p.

CADMAN, D. \& AUSTIN-CROWE, L. Property Development. London, E \& FN Spon, 1994. 3rd.Ed. 163p.

CASAROTTO FILHO, N.; KOPITTKE, B. H.. Analise de Investimentos. Editora Atlas, São Paulo. 2010. 11 edição. 408 p.

CONAMA. Resolução n. 430, de 13 de maio de 2011. Dispõe sobre as condições e padrões de lançamento de efluentes, complementa e altera a Resolução no 357, de 17 de março de 2005, do Conselho Nacional do Meio Ambiente- CONAMA.

CUENCA, M. A. G.; RESENDE, J. M.; SAGGIN JÚNIOR, O. J. et al. Mercado brasileiro do coco: situação atual e perspectivas. In: ARAGÃO, W. M. Coco: póscolheita. Brasília, DF: Embrapa Informação Tecnológica, 2002. p. 11-18.

EMBRAPA. Evolução da produção de coco no Brasil e o comércio internacional: panorama 2010. Carlos Roberto Martins, Luciano Alves de Jesus Júnior - Aracaju: Embrapa Tabuleiros Costeiros, 2011.

FAO 2011. World Production. Disponível em: <www.faostat.org.br>. Acesso em: janeiro de 2012.

HIRSCHFELD, H. Engenharia Econômica. São Paulo, Atlas, 1984. 3a.Ed. 440p.

IBGE. Produção Agrícola Municipal. Disponível em: <http:www.sidra.ibge.gov. br/bda/pesquisa>. Acesso em: janeiro de 2012.

MAGAlHAES, A. L. R. Cana-de-Açúcar em Substituição à Silagem de Milho em Dietas para Vacas em Lactação: Desempenho e Viabilidade Econômica. R. Bras. Zootec., v.33, n.5, p.1292-1302, 2004. 
MARQUEZAN, L H. F.; BRONDANI, G. Análise de investimentos. Revista Eletrônica de Contabilidade Curso de Ciências Contábeis UFSM. VOL. iii n. 1 jan-jun/2006.

MORORÓ, R. Industrialização do coco. Revista tecnologia e treinamento. Disponível em: <http://www.tenologiaetreinamento.com.br>. Acesso em: Março de 2012.

SAMANEZ, Carlos Patrício. Matemática Financeira - Aplicações à Análise de Investimentos. 3. ed. São Paulo: Prentice Hall, 2002.

TEIXEIRA, E. A. M. et al. Estudo do processamento e estabilidade de coco ralado. Boletim do Centro de Pesquisa de Processamento de Alimentos, Vol. 3, No 1 (1985). 